\title{
Clinical course \& management of childhood nephrotic syndrome in Germany: a large epidemiological ESPED study
}

Ingo Franke ${ }^{1 \dagger^{\wedge}}$, Malik Aydin ${ }^{1,2^{*}}$ (D), Lisa Kurylowicz ${ }^{1}$, Corinna Elke Llamas Lopez ${ }^{1}$, Rainer Ganschow ${ }^{1}$, Michael J. Lentze ${ }^{1}$ and Mark Born ${ }^{3}$

\begin{abstract}
Background: Nephrotic syndrome (NS) is one of the most frequent occurring chronic kidney diseases in childhood, despite its rarely occurrence in the general population. Detailed information about clinical data of NS (e.g. average length of stay, complications) as well as of secondary nephrotic syndrome (SNS) is not well known.

Methods: A nationwide ESPED follow-up study presenting the clinical course and management of children with NS in Germany.

Results: In course of 2 years, 347 children developed the first onset of NS, hereof 326 patients (93.9\%) had a primary NS, and 19 patients had a SNS (missing data in 2 cases), the majority due to a Henoch-Schönlein Purpura. Patients with steroid-resistant NS (SRNS) stayed significantly longer in hospital than children with steroid-sensitive NS (25.2 vs. $13.3 \mathrm{~d}, p<0.001)$. Patients with bacterial/viral infections stayed longer in hospital ( $24.9 \mathrm{~d} / 19.5 \mathrm{~d})$ than children without an infection (14.2 d/14.9 d; $p<0.001 ; p=0.016)$. Additionally, children with urinary tract infections (UTI) $(p<0,001)$, arterial hypertension (AH) $(p<0.001)$ and acute renal failure (ARF) $(p<0,001)$ stayed significantly longer in hospital.

Patients with SRNS had frequent complications ( $p=0.004)$, such as bacterial infections $(p=0.013)$, AH $(p<0.001)$, UTI $(p<0.001)$ and ARF $(p=0.007)$. Children with a focal segmental glomerulosclerosis (FSGS) had significantly more complications ( $p=0.04)$; specifically bacterial infections $(p=0.01)$, UTI $(p=0.003)$ and AH $(p<0,001)$. Steroidresistance was more common in patients with UTI $(p<0.001)$ and in patients with ARF $(p=0.007)$. Furthermore, steroid-resistance $(p<0.001)$ and FSGS $(p<0.001)$ were more common in patients with AH.

Conclusions: This nationwide, largest German study presents results on the clinical course of children with NS considering a diverse range of complications that can occur with NS. The establishment of a region-wide and international pediatric NS register would be useful to conduct further diagnostic and therapy studies with the aim to reduce the complication rate and to improve the prognosis of NS, and to compare the data with international cohorts.
\end{abstract}

Keywords: Primary nephrotic syndrome, Secondary nephrotic syndrome, Childhood, ESPED, Complication

\footnotetext{
* Correspondence: malik.aydin@uni-wh.de

This present work has already been defended as a doctoral thesis by Corinna Elke Llamas Lopez

${ }^{\dagger}$ Ingo Franke and Malik Aydin contributed equally to this work.

Deceased

'Department of General Pediatrics, Division of Pediatric Nephrology, University Children's Hospital Bonn, Bonn, Germany

${ }^{2}$ Helios University Medical Center Wuppertal, Children's Hospital, Center for Clinical and Translational Research (CCTR), Center for Biomedical Education and Research (ZBAF), Witten/Herdecke University, Heusnerstr. 40, 42283 Wuppertal, Germany

Full list of author information is available at the end of the article
}

(c) The Author(s). 2019 Open Access This article is distributed under the terms of the Creative Commons Attribution 4.0 International License (http://creativecommons.org/licenses/by/4.0/), which permits unrestricted use, distribution, and reproduction in any medium, provided you give appropriate credit to the original author(s) and the source, provide a link to the Creative Commons license, and indicate if changes were made. The Creative Commons Public Domain Dedication waiver (http://creativecommons.org/publicdomain/zero/1.0/) applies to the data made available in this article, unless otherwise stated. 


\section{Background}

Although nephrotic syndrome (NS) is rarely observed in the general population, it is one of the most frequent chronic kidney diseases in childhood. There have been a number of epidemiological studies focusing on childhood NS and it has been shown that the incidence in childhood varies worldwide. In Germany, the reported incidence of NS is $1.2-1.8$ per 100,000 children per year [1] in comparison to $3-3.5$ per 100,000 children living in Paris and the surrounding area [2] and to 6.49 per 100,000 children per year in Japan [3].

However, only few studies focus on epidemiological data, i.e. clinics at onset, hospital duration and complications in patients with primary (PNS) and secondary NS (SNS). This epidemiological study continues and examines the clinical course and management of childhood NS in our large ESPED (Erhebungseinheit für Seltene Pädiatrische Erkrankungen in Deutschland/ survey unit for rare pediatric diseases in Germany)-based German cohort.

\section{Methods}

We performed an epidemiological study through an ESPED-based survey from 01.01.2005 until 31.12.2006 including all hospitalized children in the age range of 0 to 18 years in Germany with the first onset of NS (hypalbuminuria $<25 \mathrm{~g} / \mathrm{l}$, high proteinuria $>40 \mathrm{mg} / \mathrm{m}^{2} / \mathrm{h}$, accordingly to $1 \mathrm{~g} / \mathrm{m}^{2} / \mathrm{d}$ and edema) registered by ESPED.

ESPED received a notification of all patients with NS from each hospital and returned to the reporting hospital a questionnaire regarding the patient's data, history and any complications (Additional file 1). The questionnaire was completed and sent then back pseudonymously to ESPED in Düsseldorf/Germany. The questionnaire was designed by the Society of Pediatric Nephrology (Arbeitsgemeinschaft für Pädiatrische Nephrologie, APN) in accordance with the German data protection laws. All analyzed data involving human participants were in accordance with the ethical standards and with the 1964 Helsinki declaration and its later amendments or comparable ethical standards. Ethical approval was obtained by the Faculty of Medicine, Rheinische Friedrich-Wilhelms-University, Bonn/Germany Ethics Committee and the study was assigned the human study registration number 081/05. The data extraction and analyzes were performed pseudonymously. Additionally, a telephone survey with pediatricians and nephrologists in the zip code area beginning with 5 in Germany was conducted to identify any possibly missed notification to ESPED [1]. Caregivers provided written informed consent for the patient's inclusion in the study. All patient's families gave their written informed consent to their inclusion in the study.

\section{Statistics}

Statistical analyses were conducted using IBM ${ }^{\bullet}$ SPSS version 18.0 (NY, USA). t-tests were used for two independent samples and a One-way ANOVA for more than 2 independent samples was used. The significance level was set at $p<0.05$. The department of statistics provided epidemiological data used to calculate the incidence of NS. The reported data was given as mean \pm Standard Deviation. Comparisons of categorial variables were performed using the Chi-square and Fisher's Exact tests. Missing values were excluded from the statistical analysis.

\section{Results \\ Primary nephrotic Syndrome \\ Description of patients}

347 children were recruited for the present study in the period of 2 years. 326 patients $(93.9 \%)$ had a primary (idiopathic) NS. Nineteen patients (5.5\%) had SNS (for 2 patients the form of NS was unknown). The average age of the study sample was $5.5 \pm 3.7$ years $(n=346$, the age for one patient was unknown). $10.5 \%$ of the children were of Turkish origin and represents the largest ethnic minority of the study cohort $(n=36)$. Within the study sample, totally 282 patients $(81.3 \%)$ had a steroid-sensitive nephrotic syndrome (SSNS) and 51 steroid-resistant nephrotic syndrome (SRNS). Twelve patients did not have steroid therapy, for which the reasons are not known and for 2 patients, it is unknown if they received steroid therapy. The incidence of SSNS was 1 per 100,000 and of SRNS was 0.2 per 100,000 children $<18$ years in Germany (Table 1) [1].

Table 1 Description of demographic parameters (age, gender and ethnicity) of the study cohort, $n=347$

\begin{tabular}{ll}
\hline Primary nephrotic syndrome (PNS) & 326 \\
\hline Secondary nephrotic syndrome (SNS) & 19 \\
Missing information & 2 \\
Male & 222 \\
Female & 125 \\
Gender ratio & $1.8: 1$ \\
Mean age & $5.5 \pm$ SD 3.7 years \\
Steroid sensitive nephrotic syndrome & 282 (Mean age = 5.5 years) \\
Steroid resistant nephrotic syndrome & 51 (Mean age = 6.1 years) \\
No steroid therapy & 12 \\
Ethnicity & \\
German (PNS/SNS) & $215 / 14$ \\
Non-German & $109 / 4$ \\
Missing information & 4 \\
Origins & \\
Turkish & 36 \\
Russian & 69 \\
Others &
\end{tabular}


Table 2 Number of individual complications for patients with NS, $n=347$

\begin{tabular}{llll}
\hline Complication & Yes & No & $\boldsymbol{\Sigma}$ \\
\hline Peritonitis & $3(0.9 \%)$ & $344(99.1 \%)$ & 347 \\
Phlegmon & $2(0.6 \%)$ & $345(99.4 \%)$ & 347 \\
Sepsis & $3(0.9 \%)$ & $344(99.1 \%)$ & 347 \\
Lower Respiratory Tract & $22(6.3 \%)$ & $325(93.7 \%)$ & 347 \\
Infection & & & \\
Urinary Tract Infection & $8(6.3 \%)$ & $339(97.7 \%)$ & 347 \\
Tonsillitis & $6(1.7 \%)$ & $341(98.3 \%)$ & 347 \\
Upper Respiratory Tract & $12(3.5 \%)$ & $335(96.5 \%)$ & 347 \\
Infection & & & \\
Gastroenteritis & $28(8.1 \%)$ & $319(91.9 \%)$ & 347 \\
Varizella Zoster Virus & $3(0.9 \%)$ & $344(99.1 \%)$ & 347 \\
infection & & & \\
Hepatitis & $1(0.3 \%)$ & $346(99.7 \%)$ & 347 \\
Acute Kidney Failure & $15(4.3 \%)$ & $332(95.7 \%)$ & 347 \\
Arterial hypertension & $34(9.8 \%)$ & $313(90.2 \%)$ & 347 \\
Hypothyroidism & $17(4.9 \%)$ & $330(95.1 \%)$ & 347 \\
Thrombosis & $1(0.3 \%)$ & $346(99.7 \%)$ & 347 \\
Vasculitis & $1(0.3 \%)$ & $346(99.7 \%)$ & 347 \\
\hline
\end{tabular}

\section{Complications of NS}

After the onset of NS, one or more complications arose in 106 patients (30.5\%). Twenty-eight patients had acute gastroenteritis, 22 patients had a lower airway tract infection (LRTI), 15 patients suffered from acute renal failure (ARF), 34 from hypothyroidism and 34 patients had arterial hypertension (AH) at onset of NS (Table 2).
Furthermore, 41 patients had bacterial infections, 40 patients had viral infections and 61 children had viral or bacterial infections. Ten patients had both viral and bacterial infections. The difference in length of stay for patients with viral and bacterial infections, either viral or bacterial versus no viral or bacterial infection was significant (Fig. 1).

The mean age of children with bacterial infections was 4.5 years compared to children with no bacterial infections or no infection at all (5.6 years; $p=0.067$ ). The mean age of children with viral infections was 4.8 years compared to children without viral infections ( 5.6 years).

Patients with a LRTI (average age 4.1 years) were significantly younger than patients without LRTI ( 5.6 years; $p=0.014)$. LRTIs were less frequent in children of German origin in comparison to children with other ethnic origins $(p=0.026)$. Similarly, children with an urinary tract infection (UTI) were on average 3.3 years old and were younger than children who did not have an UTI $(M=5.6$ years; $p=0.084)$. These patients with UTIs had no congenital anomalies of the kidney and urinary tract. Patients with bacterial infections stayed longer in hospital $(24.9 \mathrm{~d})$ than children without a bacterial infection (14.2 d; $p<0.001)$. Furthermore, children with viral infections were hospitalized longer (19.5 d) than children without viral infections (14.9 d; $p=0.016)$.

Specifically, children with an UTI $(p<0,001)$, varicella zoster virus $(\mathrm{VZV})$ infection $(\mathrm{p}=0,032)$, ARF $(p<0,001)$ and $\mathrm{AH}(p<0,001)$ stayed significantly longer in hospital than children without these complications. Complications occurred more commonly in patients with SRNS

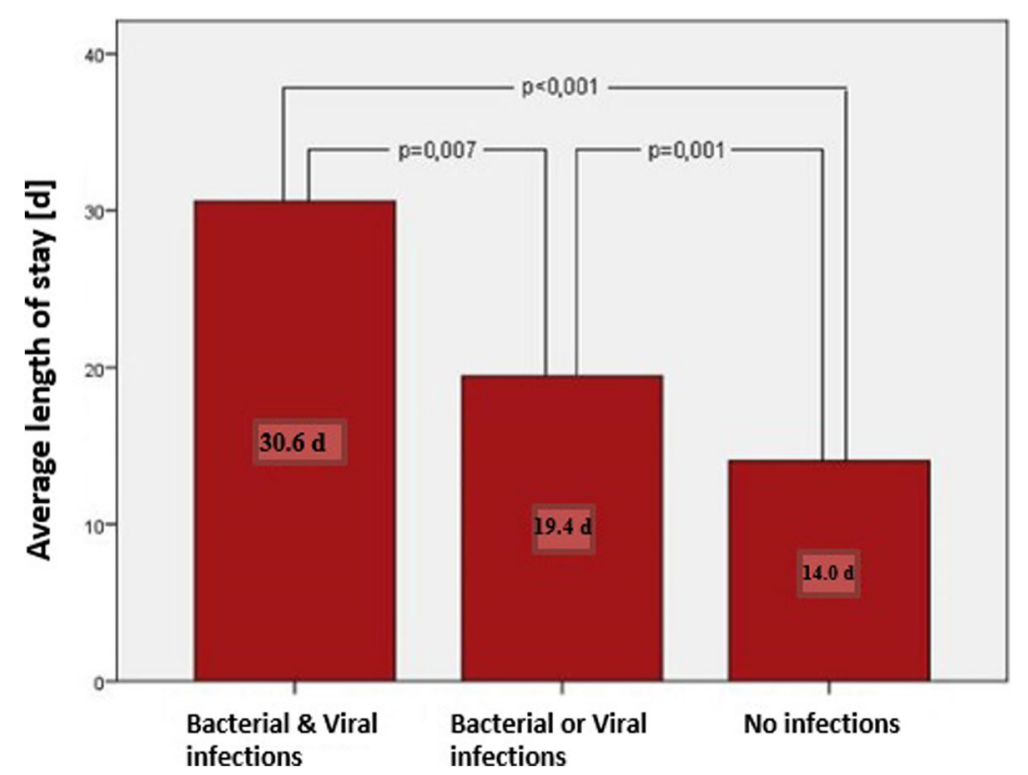

Fig. 1 Average length of stay in hospital for children with NS and bacterial and/or viral infections or no infection, $n=344$ 
than in children with SSNS $(p=0.013)$. In $65 \%$ (69 patients, $n=106)$ of cases, children with complications were of German origin, and 33\% (35 of 104 patients) of cases were of other ethnic origins and the ethnic origin of 2 (2\%) patients was unknown. 67.4\% (161 of 239 patients) of German patients had no complications.

Steroid-resistance was more common in patients with UTI $(p<0.001)$ and in patients with $\operatorname{ARF}(p=0.007)$. Furthermore, steroid-resistance $(p<0.001)$ and focal segmental glomerulosclerosis (FSGS) $(p<0.001)$ were more common in patients with $\mathrm{AH}$.

Seventy-six $(22 \%, n=343)$ patients had kidney biopsies, with $31.4 \%$ of patients with at least complication and $18.1 \%$ of patients without complications having biopsies $(p=0.006)$. Patients with an UTI were more likely to have a histological examination than patients without an UTI $(p=0.001)$. Also, patients with ARF had frequently more kidney biopsies than patients with a normal renal function $(p=0.001)$. Children who were diagnosed with $\mathrm{AH}$ at NS onset were also more likely to be biopsied than those patients who had blood pressure values within the normal range $(p<0.001)$. Over half of all patients with $\mathrm{AH}$ were biopsied (18/34, 52.9\%), whereas $18.8 \%(58 / 309)$ of children without $\mathrm{AH}$ were biopsied.

Seven (30\%) of the 23 patients with histologically confirmed FSGS had bacterial infections. Ten percent of patients without FSGS had bacterial infections, indicating children with FSGS were more likely to have bacterial infections $(p=0.01)$. More specifically, an increased number of UTIs were diagnosed in patients with FSGS $(p=0.008)$ and, significantly more patients with FSGS had AH $(p<0.001)$ (Table 3).

In comparison to patients with minimal-change-glomerulonephritis (MCNS, both biopsy-confirmed or assumed), patients with FSGS had significantly more complications $(p$ $=0.04)$, specifically bacterial infections $(p=0.01)$, UTI $(p=$ $0.003)$ and $\mathrm{AH}(p<0,001)$.

Furthermore, ARF was tendentially more frequent in histologically diagnosed MCNS patients than compared to non-biopsied children $(p=0.056)$. Of the 19 patients with SNS, 9 patients had complications, 10 patients had no complications. Of the patients with PNS $(n=326), 96$ patients had complications and 230 patients had no

Table 3 Complications arising in children presenting for the first time with Nephrotic syndrome, with and without focal segmental glomerulosclerosis (FSGS), $n=342$ (missing information for 4 patients)

\begin{tabular}{|c|c|c|c|c|c|}
\hline & & FSGS & No FSGS & $\Sigma$ & $p$-value \\
\hline \multirow[t]{2}{*}{ Peritonitis } & No & $22(6.5 \%)$ & $317(93.5 \%)$ & 339 & \\
\hline & Yes & 1 (33.3\%) & $2(66.7 \%)$ & 3 & 0.189 \\
\hline \multirow[t]{2}{*}{ Phlegmon } & No & $22(6.5 \%)$ & $318(93.5 \%)$ & 340 & \\
\hline & Yes & $1(50.0 \%)$ & $1(50.0 \%)$ & 2 & 0.130 \\
\hline \multirow[t]{2}{*}{ Sepsis } & No & $23(6.8 \%)$ & $316(93.2 \%)$ & 339 & \\
\hline & Yes & & $3(100.0 \%)$ & 3 & 1.000 \\
\hline \multirow[t]{2}{*}{ Lower Respiratory Tract Infection } & No & $20(6.2 \%)$ & $300(93.8 \%)$ & 320 & \\
\hline & Yes & $3(13.6 \%)$ & $19(86.4 \%)$ & 22 & 0.176 \\
\hline \multirow[t]{2}{*}{ Urinary Tract Infection } & No & $20(6.0 \%)$ & $315(94.0 \%)$ & 335 & \\
\hline & Yes & $3(42.9 \%)$ & $4(57.1 \%)$ & 7 & 0.008 \\
\hline \multirow[t]{2}{*}{ Upper Respiratory Tract Infection } & No & $22(6.7 \%)$ & $308(93.3 \%)$ & 330 & \\
\hline & Yes & $1(8.3 \%)$ & $11(91.7 \%)$ & 12 & 0.572 \\
\hline \multirow[t]{2}{*}{ Varizella Zoster Virus infection } & No & $22(6.5 \%)$ & $317(93.5 \%)$ & 339 & \\
\hline & Yes & $1(33.3 \%)$ & $2(66.6 \%)$ & 3 & 0.189 \\
\hline \multirow[t]{2}{*}{ Acute Renal Failure } & No & $22(6.7 \%)$ & $305(93.3 \%)$ & 327 & \\
\hline & Yes & $1(6.7 \%)$ & $14(93.3 \%)$ & 15 & 1.000 \\
\hline \multirow[t]{2}{*}{ Arterial hypertension } & No & $14(4.5 \%)$ & $294(95.5 \%)$ & 308 & \\
\hline & Yes & $9(26.5 \%)$ & $25(73.5 \%)$ & 34 & $<0.001$ \\
\hline \multirow[t]{2}{*}{ Hypothyroidism } & No & $20(6.2 \%)$ & $305(93.8 \%)$ & 325 & \\
\hline & Yes & $3(17.6 \%)$ & $14(82.4 \%)$ & 17 & 0.097 \\
\hline \multirow[t]{2}{*}{ Thrombosis } & No & $23(6.7 \%)$ & $318(93.3 \%)$ & 341 & \\
\hline & Yes & & $1(100 \%)$ & 1 & 1.000 \\
\hline \multirow[t]{2}{*}{ Vasculitis } & No & $23(6.7 \%)$ & $318(93.3 \%)$ & 341 & \\
\hline & Yes & & 1 & 1 & 1.000 \\
\hline
\end{tabular}


complications $(p=0.099)$ Three patients with SNS had a tonsillitis, these 3 patients had a bioptically proofed poststreptococcal glomerulonephritis. In total, 6 patients had a tonsillitis. Thus, $50 \%$ of the patients with SNS had significantly more tonsillitis than PNS $(p=0.003)$. All other complications, in contrast to patients with PNS, did not occur significantly more or less frequently in patients with SNS (Table 3).

The current guidelines recommend, that children with SSNS should not undergo a biopsy. In our study cohort, a biopsy was conducted in 76 patients $(21.9 \% ; n=347)$. 31 patients had MCNS and 23 patients had FSGS. In addition, 5 patients had diffuse mesangial sclerosis (DMS) and further 5 children had Henoch-Schönlein purpura (HSP). Three patients had histopathologically an IgA-Nephritis; mesangioproliferative GN was diagnosed in 2 patients, and each one patient suffered from an immune complex nephritis, membranoproliferative GN, MGN Type 2 and diffuse proliferative GN. For 3 patients, the histo-pathology is unknown. When patients without biopsies but with SSNS are added, the estimated incidence of MCNS is then $85.5 \%$. Patients who underwent a biopsy were significantly older than patients without the biopsy (6.7 years versus 5.2 years, $p=0.011$ ).

The comparison of the average age of patients with MCNS, FSGS, DMS, HSP and IgA nephropathy revealed a significant difference $(p=0.002)$. Children with DMS were averaged 1.3 years younger than those patients with a MCNS $(p=0.015)$, FSGS $(p=0.029)$ and HSP-nephritis $(p=0.037)$. More children beyond the age of 10 years had a histo-pathologically confirmed FSGS compared to children < 10 years of age $(\mathrm{p}=0.029)$. Of the 76 histo-pathologically examined patients, FSGS was commonly more present in girls $(n=15)$ in comparison to boys $(n=8 ; p=0.021)$. The ALOS was significantly longer for children with FSGS compared to all other patients having NS (27.7 d; $p=0.001)$. Analyzing the data of the biopsied patients, 49 (65.3\%) children were steroid-resistant and 22 children were steroid-sensitive (29.3\%). 22 patients with FSGS at onset were steroid-resistant (95.7\%), only one patient with FSGS (4.3\%) initially had SSNS [1].

\section{Average length of stay}

The Average length of stay (ALOS) was $15.5 \pm 11.2$ days (Median: $12.0 \mathrm{~d}$ ) [1]. Twenty-five percent of the children had a length of stay of 9 days and less and 25\% were hospitalized for more than 18 days. Seven children were treated as outpatients, or rather daily in-patients (length of stay $=1$ day) (Fig. 2). The ALOS of children of 2 years and less was $19.3 \mathrm{~d}$, which is significantly longer than for children aged 3 years and older $(14.2 \mathrm{~d}, p=0.004)$. Furthermore, the ALOS increased in older children, with children aged 12-14 years staying an average of $16.8 \mathrm{~d}$ and children aged 15-18 years staying an average of 20.1 d. A significant difference between the age groups is shown between 0 and 2 years-old and $3-5$ years-old $(p=$ $0.021)$, the $0-2$-years-old and 6-8-years-old $(p=0.003)$ and the 0-2-years-old and the 9-11-years-old $(p=$ 0.022) (Fig. 2). The ALOS in hospital for boys was 14.7 $\mathrm{d}$ and $16.8 \mathrm{~d}$ for girls $(p=0.098)$. Children with German origins had an ALOS of $16.1 \mathrm{~d}$ and children with other ethnic origin was $14.3 \mathrm{~d}(p=0.135)$. The ALOS of patients with complications was significantly longer (20.5 days) than for patients without complications (13.2 days; $p=0.001) .21 .6 \%$ of patients with SRNS and $9.5 \%$ of

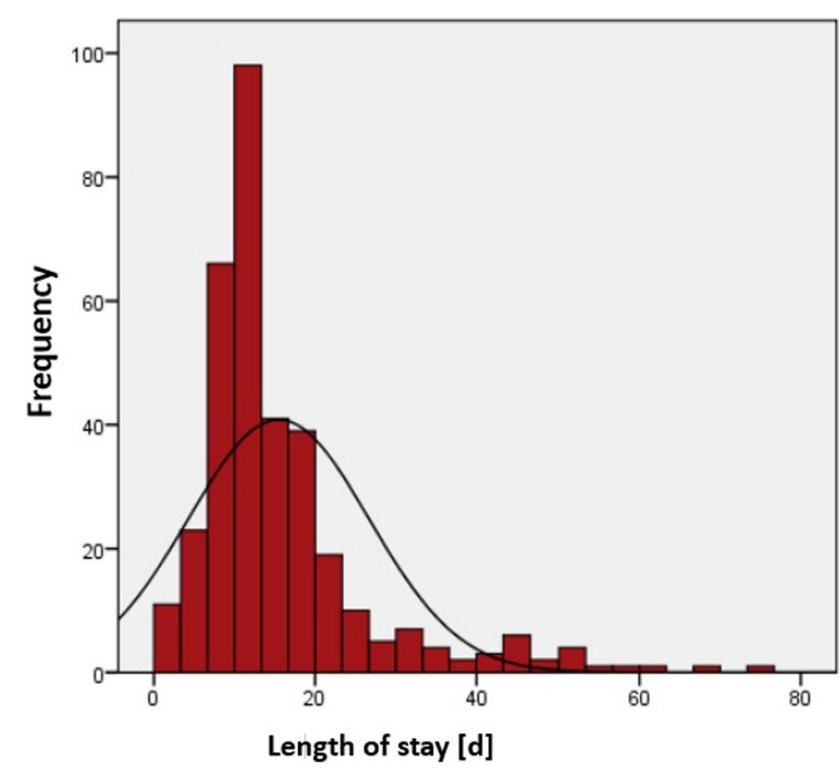

Mean $=15.47$

$\mathrm{SD}=11.239$

$\mathrm{N}=345$

Fig. 2 Distribution of length of stay at initial onset of NS, $n=345$ 
patients with SSNS had bacterial infections, with SRNS patients having significantly more bacterial infections than patients with SSNS $(p=0.013)$.

\section{Secondary nephrotic Syndrome}

Nineteen patients $(5.5 \%)$ had SNS $(n=347)$. Of these, 8 patients developed SNS due to HSP, 5 patients had SNS in the course of an acute streptococcal infection, 3 patients had a glomerulonephritis with a nephrotic component, in 1 patient NS occurred in the realm of Hepatitis $\mathrm{C}(\mathrm{HCV})$, in 1 patient due to Epstein-Barr virus, and in 1 patient due to a Parvo-Virus B 19 infection.

The average age of patients with SNS was 6.3 years in comparison to 5.5 years for patients with PNS. Table 4 shows the gender distribution of patients with SNS. $77.8 \%$ of patients with SNS were of German origin, $22.2 \%$ had other ethnic origins. Comparatively, $66.4 \%$ of patients with PNS were of German origin and 33.6\% had other ethnic backgrounds.

The ALOS of patients with SNS was $13.8 \mathrm{~d}$, while the children with PNS stayed in hospital an average of 15.6 days. $21.1 \%$ of patients with SNS had SRNS, $42.1 \%$ had SSNS, $36.8 \%$ of patients received no steroids. In comparison, $14.5 \%$ of patients with PNS had SRNS, $84.0 \%$ had a SSNS, and only $1.5 \%$ were not treated with steroids. Significantly more children with PNS were treated with steroids than children with SNS $(p<0.001)$.

Among the patients with PNS, a histological sample was taken from 68 of $323(21.1 \%)$ patients. Five patients with SNS had a histologically confirmed HSP nephritis, 1 patient had an immunocomplex nephritis with Parvo-Virus-B 19 infection, and one patient had a diffuse proliferative glomerulonephritis due to HSP.

\section{Discussion}

Although one of the rarer diseases in children, NS is not unknown among the vast majority of physicians in many countries, including Germany. Literature about the epidemiology and incidence of NS vary, depending on the country and the ethnic origin of the children.

In the present study, children less than 3 years of age stayed significantly longer in hospital at onset than older children, most likely due to the higher rate of bacterial infections. Interestingly, the ALOS increased for children over 12 years of age (Fig. 3) possibly due to the fact, that

Table 4 Gender distribution of patients with secondary nephrotic syndrome (SNS) \& primary nephrotic syndrome (PNS), $n=345$

\begin{tabular}{llll}
\hline & SNS & PNS & $\Sigma$ \\
\hline Female & $4(21.1 \%)$ & $121(37.1 \%)$ & $125(36.2 \%)$ \\
Male & $15(77.9 \%)$ & $205(62.9 \%)$ & $220(63.8 \%)$ \\
$\boldsymbol{\Sigma}$ & $19(100.0 \%)$ & $326(100.0 \%)$ & $345(100.0 \%)$ \\
\hline
\end{tabular}

the complication rate in this age group is higher compared to the other age groups. Furthermore, the ALOS of girls was 16.0 days slightly compared to boys with 15.0 days, although girls were more likely to have SRNS and FSGS. Schlesinger et al. also examined the length of stay in hospital for patients with NS. In comparison, the ALOS was 27.1 days with a median of 19 days. Notably, male patients had an ALOS in hospital twice as long as female patients, and children with dark skin had three times longer hospital stay than children with light skin. Over the past years, there is a trend indicating that the average number of days in hospital decreases [4]. One reason for the increase in the ALOS is that steroid resistance is more present in older aged children. Ethic differences in the ALOS have also been reported $[1,5]$.

Complications arise for some patients with NS. For 106 patients (30.5\%) in the current cohort complications arose, of which $66.3 \%$ of the children were of German origins and $33.7 \%$ were of other ethnic origins. Ethnic differences in the appearance of onset of SSNS and SRNS or MCNS and FSGS have been found in the literature worldwide, especially between light- and dark-skinned children. Many authors have already shown that African and African-American children were more likely to have FSGS or SRNS than Caucasians [6-9]. Hispanic-American children in New York were more likely to have FSGS than Caucasians and as often as African-American children [7]. Furthermore, in a study by Bonilla-Felix et al., Hispanic-American children in Houston had a lower incidence of FSGS than AfricanAmerican and Caucasian children [6].

The rate of infections also appears to differ across population groups. In a population study from Paris and its surrounding areas, $8 \%$ of all patients with NS had bacterial infections that required treatment with intravenous antibiotic therapy. The most frequent infection was peritonitis, followed by pyelonephritis and pulmonary infection [10]. Peritonitis was rarely seen in our study with $0.9 \%$. However, in line with the Paris and surrounding, bacterial infections in patients with SRNS were seen more often than in patients with SSNS. In comparison, in India 39\% of patients had infections. The most common infection was upper respiratory tract infection (URTI) (13.7\%), followed by lung tuberculosis $(10.4 \%)$ and peritonitis (9.1\%). In a study by Yap et al., children with steroid-dependent NS in Singapore were more likely to have an URTI [11] and Alwadhi et al. reported that $70.6 \%$ of children with NS in India had infections, mostly UTI and empyema [12]. Moreover, Ibadin et al. also reported that $44.8 \%$ of patients with NS had a UTI [13] however, only $2.3 \%$ of our patients in the present study had a UTI. An UTI occurred significantly more frequently in patients with SRNS or FSGS. Children with a LRTI in the present cohort were 


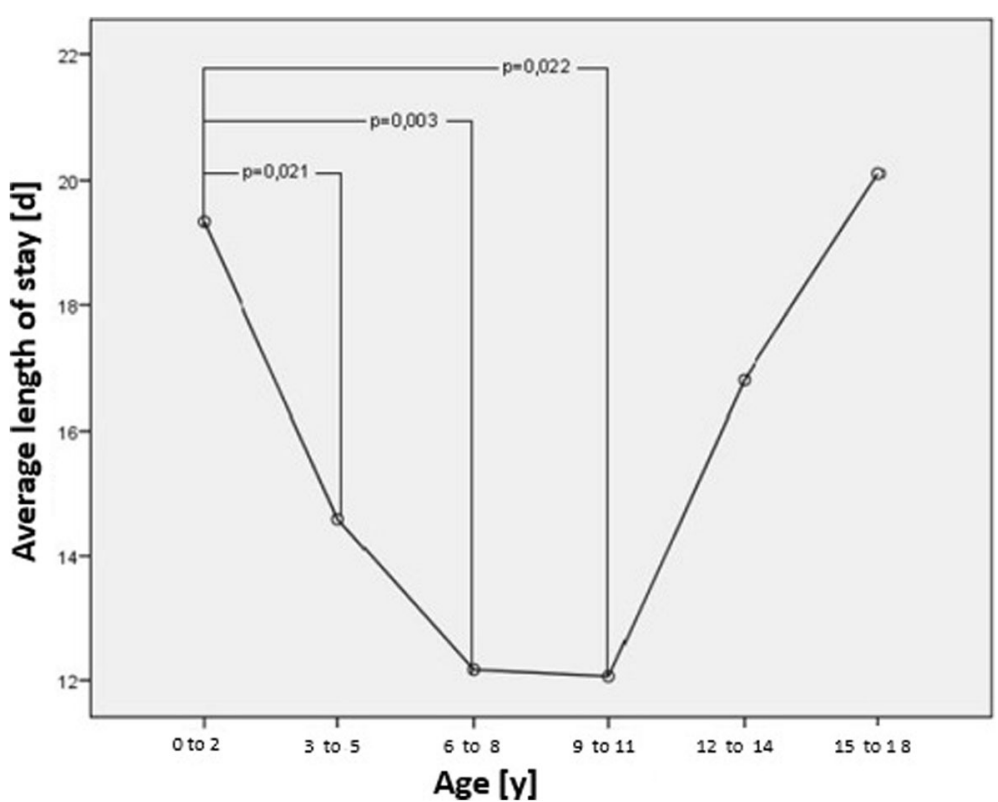

Fig. 3 Average length of stay in hospital for patients in different age groups at initial onset of NS, $n=344$

significantly younger than those without LRTI. The overall trend is that children with bacterial infections are younger. Also, the number of the infections was mostly associated to the number of relapses of NS [14].

Complications in children with intrauterine growth restriction (IUGR) were significantly higher and multiple studies have also reported about the association of SRNS and AH in children with IUGR [15-17]. Children with NS and IUGR were reported to have pneumonia, peritonitis and $\mathrm{AH}$ more frequently [15]. Arterial hypertension was observed in 34 of our patients $(9.8 \%)$, who often had SRNS and FSGS, although no patient in this cohort had IUGR. Davutoglu et al. similarly reported that children with $\mathrm{AH}$ were frequently more steroid-resistant [14]. Importantly, AH has rarely been observed in children with MCNS [18] but was more common in children with FSGS [19].

Interestingly, hypothyroidism was present in 17 (4.9\%) of the cases in the present study. An untreated NS is mostly associated with a hypothyroidism due to the renal loss of TGB, fT3, fT4, T3 and T4 [20]. In total, there is limited literature investigating the relationship between renal disorders and hypothyroidism, with the majority of the literature only describing specific cases. However, in a recent study from India, renal biopsy findings from patients with previously diagnosed hypothyroidism were examined. Of the 16 patients with hypothyroidism, 7 (43.75\%) patients had membranous glomerulonephritis (MGN), 4 patients (25\%) had both mesangial cell proliferation and MGN. A further 4 cases (25\%) had FSGS with chronic interstitial nephritis and only one patient had MCNS. These results also demonstrate hypothyroidism is a common diagnosis presented in patients with NS, in consideration, that $81.25 \%$ of patients of the Indian study had NS, and predominantly MGN [13]. It is possible that complicated courses of NS also influence the hormonal status of a patient due to the loss of the thyroid hormones. Further studies are required to establish the relationship between a severe clinical course of NS and hypothyroidism. Thus, physicians should take the thyroid gland into consideration during their diagnostics and therapies of patients with an onset of NS.

In this cohort, ARF was more common in steroid-resistant children than the steroid-sensitive children. At initial onset, 15 patients (4.3\%) developed ARF and FSGS did not occur more frequently in these patients. In some studies, this number has been as low in Poland and Nigeria $(0.8-1.7 \%)$ [21, 22], however in India $17.5 \%$ of biopsied patients had ARF at the initial onset of NS [23]. These differences may most likely be explained by the composition of the patient groups.

Furthermore, 22 patients were diagnosed with FSGS and only one patient with FSGS initially had SSNS. It has been previously shown that $75 \%$ of steroid-resistant NS patients had FSGS $[24,25]$. However, Nammalwar et al. reported that $32.9 \%$ of all patients with SRNS had FSGS in their study [26].

Naturally, complications can extend the ALOS in hospital. Children with SRNS stayed significantly longer in hospital (25.2 days) than children with SSNS (on average 13.3 days). This may be attributed to the more difficult therapy and the occurring complications observed in patients with SRNS. Except for one child with SRNS (presented with congenital nephrotic syndrome), all 
steroid-resistant children were biopsied in our study which can also prolong the ALOS.

North American and European literature show that over $90 \%$ of children with NS have idiopathic NS [27]. Similar results were found in our study; $93.9 \%$ of children had primary NS and 5.5\% had SNS, mostly due to HSP. HSP has also been reported to the predominant reason for secondary glomerulonephritis in children in Croatia and Korea $[28,29]]$. In most of the cases, HSP nephritis was associated with isolated hematuria, whereas NS was the exception [30,31]. Coppo et al. reported that $35 \%$ of children with HSP developed a NS, although only $24.3 \%$ adults developed NS. The male to female ratio in children with HSP was 1.44: 1 [32]. Counahan et al. reported that a nephritic and nephrotic component seen in HSP were mostly associated with a poorer diagnosis [19]. In the present study, the second most frequent cause of SNS was a streptococcal infection. In the literature, NS is rarely observed in post-streptococcal glomerulonephritis, although proteinuria has frequently been seen [33-35]. A link between the presentation of NS and a poor long-term prognosis has previously been shown $[35,36]$. Al-Rasheed et al. reported that $60 \%$ of patients with bioptically confirmed HSP nephritis had NS, but no patient had a histologically confirmed post-streptococcal GN [35]. Choi et al. reported that in Korea that $0.9 \%$ of 213 children with NS had a post-streptococcal GN [29] compared to the current data, where approximately $1.8 \%$ of patients had poststreptococcal GN.

On the other hand, the pathogenesis of PNS and SNS is very different in Africa. Infectious diseases such as Human Immunodeficiency Virus (HIV), HCV, malaria, syphilis, schistosomiasis and tuberculosis have been reported to be the main causes of NS [37-39]. In South Africa, for example, Hepatitis B virus (HBV) was the most frequent cause of NS $[23,40]$. Buuren et al. reported that 29 out of 70 children in Namibia with NS were HBV carriers, and 2 patients had syphilis [41]. Interestingly, almost all HBV-positive children showed MGN by histology. In South Africa, the rate of MGN was $20 \%$ and mostly associated with HBV; and regional differences reported (e.g. $13.5 \%$ in Johannesburg and $40.2 \%$ in Durban). FSGS was also common and $40 \%$ of FSGS children were previously treated due to a tuberculosis infection and only one patient was HIV positive [42].

In West and East Africa, however, Malaria was commonly associated with NS [43]. Anochie et al. reported that $60 \%$ of patients from Nigeria with NS were infected with Plasmodium falciparum, two patients had HIV, one had tuberculosis, and one patient had a sickle cell anemia. No patient was HBV positive [44]. In a study by Eke and colleagues, 13 of 102 patients with NS had Plasmodium malariae, 9 patients had HBV, and 2 had sickle cell anemia [45]. This number was even up to $38.7 \%$ of all children with NS, $13.3 \%$ had a sickle cell anemia [46].

Beside the clinical aspects, NS is mostly associated with considerable costs and presents a burden for the health care system. It is particularly characterized by a considerable hospital stay. On average, the costs of one patient with an onset of NS (DRG; ICD-10 for N04.0 N04.9) are approximately $1200 €$ (multiplicated with 347 patients $=416,400 €$, without complications and longer hospital stay due to other factors in Germany). Thus, depending on the kind of complication, the costs can be significantly higher.

In summary, the present epidemiological study is the largest study of this kind in children with NS with previously performed studies mostly being based on a smaller patient cohort and smaller geographical areas. Briefly, throughout the 2-year duration of the study, data for 347 patients was evaluated. The study provides answers to various epidemiological questions, in particular, regarding SNS, complication rates and the ALOS in relation to patients' gender, ethnicity and age in Germany. The data is novel in both its quality and quantity. To date, we are not aware of a similar study with a similar cohort (14 million inhabitants < 18 years in Germany). Whilst the study was conducted several years ago, recently published data on a nationwide level and with a large patient cohort regarding NS does not exist, particularly in Germany. Furthermore, this study can also provide a historical insight into the clinical course and management of childhood NS.

\section{Conclusion}

In consideration of the present result, there is a diverse range of complications that can occur with NS. Epidemiological and clinical data of NS in childhood, especially in Germany and in many other countries is limited. Through this large nationwide ESPED-study, novel and interesting data from children with NS in Germany has been gathered and provides a better understanding on NS in childhood and its complications. This study presents a first step for further multicenter studies with extended cohorts to better understand this actually rare but mostly observed nephrological diagnosis in childhood.

\section{Additional file}

Additional file 1: Questionnaire used during the study. (DOCX $16 \mathrm{~kb}$ )

\section{Abbreviations}

$\mathrm{AH}$ : Arterial hypertension; ALOS: Average length of stay; ARF: Acute renal failure; DGKJ: Deutsche Gesellschaft für Kinder- und Jugendmedizin;

ESPED: Erhebungseinheit für Seltene Pädiatrische Erkrankungen in Deutschland; FSGS: Focal segmental glomerulosclerosis; HBV: Hepatitis B virus; HIV: Human Immunodeficiency Virus; HSP: Henoch-Schönlein purpura; 
LRTI: Lower respiratory tract infection; MCNS: Minimal-changeglomerulonephritis; MGN: Membranous glomerulonephritis; NS: Nephrotic syndrome; PNS: Primary nephrotic syndrome; SNS: Secondary nephrotic syndrome; SRNS: Steroid-resistant nephrotic syndrome; SSNS: Steroidsensitive nephrotic syndrome; URTI: Upper respiratory tract infection; UTI: Urinary tract infection

\section{Acknowledgements}

The questionnaire was developed in consultation with the members of the Arbeitsgemeinschaft für Pädiatrische Nephrologie (APN) study committee and the survey was inaugurated as an APN-supported study. We thank the Erhebungseinheit für Seltene Pädiatrische Erkrankungen in Deutschland (ESPED) for their exceptional cooperation and collaboration.

\section{Funding}

This study was funded by Bonner Elternverein für Nierenkranke Kinder. The funding did not play any role in the design of the study and collection, analysis and interpretation of data and in writing the manuscript.

\section{Availability of data and materials}

The datasets used and/or analyzed during the current study are available from Dr. I. Franke/Dr. C.E. Llamas Lopez on reasonable request at Department of General Pediatrics, University Children's Hospital Bonn and will be shared with scientists/researcher upon request to Dr. I. Franke or Dr. C.E. Llamas Lopez.

\section{Authors' contributions}

IF designed the study. CELL, IF \& MA analyzed the data set. CELL, IF, MA, MB performed the literature search, extracted and analyzed the data and drafted the manuscript. MJL, RG \& LK participated in manuscript writing and revision. All authors have read and approved the final manuscript.

***ingo Franke $\dagger^{* * *}$.

We thank our first author, colleague and friend Ingo Franke for his excellent work in the field of Pediatric Nephrology in Germany. He taught us very enthusiastically and was a great pediatrician and researcher. Rest in Peace, Dear Ingo. We all miss you!

\section{Ethics approval and consent to participate}

All analyzed data involving human participants were in accordance with the ethical standards and with the 1964 Helsinki declaration and its later amendments or comparable ethical standards. Ethical approval was obtained by the Faculty of Medicine, Rheinische Friedrich-Wilhelms-University, Bonn/ Germany Ethics Committee and the study was assigned the human study registration number 081/05. The data extraction and analyzes were performed pseudonymously. All subjects gave their written participant informed consent to their inclusion in the study. This article does not contain any studies with animals performed by any of the authors. Caregivers provided written informed consent for the patient's inclusion in the study. All patient's families gave their written informed consent to their inclusion in the study.

\section{Consent for publication}

Not applicable.

\section{Competing interests}

The authors have declared that they have no competing interests. This work has not been published before and it is not under consideration for publication anywhere else. Its publication has been approved by all co-authors.

\section{Publisher's Note}

Springer Nature remains neutral with regard to jurisdictional claims in published maps and institutional affiliations.

\section{Author details}

'Department of General Pediatrics, Division of Pediatric Nephrology, University Children's Hospital Bonn, Bonn, Germany. ${ }^{2}$ Helios University Medical Center Wuppertal, Children's Hospital, Center for Clinical and Translational Research (CCTR), Center for Biomedical Education and Research (ZBAF), Witten/Herdecke University, Heusnerstr. 40, 42283 Wuppertal, Germany. ${ }^{3}$ Department of Radiology, Pediatric Radiology, University Hospital of Bonn, Bonn, Germany.
Received: 4 September 2018 Accepted: 25 January 2019 Published online: 07 February 2019

\section{References}

1. Franke I, Aydin M, Llamas Lopez CE, et al. The incidence of the nephrotic syndrome in childhood in Germany. Clin Exp Nephrol. 2018;22(1):126-32.

2. Dossier $C$, et al. Epidemiology of idiopathic nephrotic syndrome in children: endemic or epidemic. Pediatr Nephrol. 2016;31(12):2299-308.

3. Kikunaga K, Ishikura K, Terano C, et al. High incidence of idiopathic nephrotic syndrome in east Asian children: a nationwide survey in Japan (JP-SHINE study). Clin Exp Nephrol. 2017;21(4):651-7.

4. Gipsin DS, Messer $\mathrm{KL}$, Tran $\mathrm{CL}$, et al. Inpatient health care utilization in the United States among children, adolescents, and young adults with nephrotic syndrome. Am J Kidney Dis. 2013;61(6):910-7.

5. Wang CS, Yan J, Palmer R, et al. Childhood nephrotic Syndrome management and outcome: a single center retrospective analysis. Int J Nephrol. 2017;2017:2029583. https://doi.org/10.1155/2017/2029583.

6. Bonilla-Felix M, Parra C, Dajani T, et al. Changing patterns in the histopathology of idiopathic nephrotic syndrome in children. Kidney Int. 1999:55:1885-90.

7. Ingulli E, Tejani A. Racial differences in the incidence and renal outcome of idiopathic FSGS in children. Pediatr Nephrol. 1991:5:393-7.

8. Sorof JM, Hawkins EP, Brewer ED, Boydstun II, Kale RS, Powell DR. Age and ethnicity affect the risk and outcome of focal segmental glomerulosclerosis. Pediatr Nephrol. 1998;12:764-8.

9. Srivastava T, Simon SD, Alon US. High incidence of focal segmental glomerulosclerosis in nephrotic syndrome of childhood. Pediatr Nephrol. 1999:13:13-8

10. Liponski I, Cochat P, Gagnadoux MF, Parchoux B, Niaudet P, David L, Broyer $M$. Bacterial infections in the nephrotic syndrome during childhood. Presse Med. 1995:24:19-22.

11. Yap HK, Han EJS, Heng C-K, Gong W-K. Risk factors for steroid dependancy in children with idiopathic nephrotic syndrome. Pediatr Nephrol. 2001;16: 1049-52.

12. Alwadhi RK, Mathew JL, Rath B. Clinical profile of children with nephrotic syndrome not on glucocorticoid therapy but presenting with infection. J Pediatr Child Health. 2004:40:28-32.

13. Ibadin MO, Epidemiology APO. Clinicopathologic characteristics of childhood nephrotic Syndrome in Benin-City. Nigeria J Pak Med Assoc. 1998;48:235-8

14. Davutoglu M, Ece A, Bilici M, Dagli A. Steroid responsiveness of children with idiopathic nephrotic syndrome in southeastern region of Turkey. Ren Fail. 2007;29:855-9.

15. Fakhouri F, Bocquet $N$, Taupin P, Presne C, Gagnadoux M-F, Landais P, et al. Steroid-sensitive nephrotic Syndrome: from childhood to adulthood. Am J Kidney Dis. 2003:41:550-7.

16. Gulati S, Sengupta D, Sharma RK, et al. Steroid resistant nephrotic Syndrome: role of histopathology. Indian Pediatr. 2006;43:55-60.

17. Teeninga N, Schreuder MF, Bökenkamp A, et al. Influence of low birth weight on minimal change nephrotic syndrome in children, including a meta-analysis. Nephrol Dial Transplant. 2008;23(5):1615-20.

18. Ehrich $\mathrm{JH}$, Brodehl J. Long versus standard prednisone therapy for initial treatment of idiopathic nephrotic syndrome in children. Arbeitsgemeinschaft für pädiatrische Nephrologie Eur J Pediatr. 1993:152:357-61.

19. Copoo R, Mazzucco G, Cagnoli L, et al. Long-term prognosis of HenochSchönlein nephritis in adults and children. Italian group of Renal Immunopathology Collaborative Study on Henoch-Schönlein purpura. Nephrol Dial Transplant. 1997;12(11):2277-83.

20. Ito S, Kano K, Ando T, Ichimura T. Thyroid function in children with nephrotic syndrome. Pediatr Nephrol. 1994:8:412-5.

21. Coovadia HM, Adhikari M, Morel-Maroger L. Clinico-pathological features of the nephrotic Syndrome in south African children. Quart J Med. 1979;189:77-91.

22. Doe JY, Funk M, Mengel M, Doehring E, Ehrich JHH. Nephrotic syndrome in African children: lack of evidence for 'tropical nephrotic syndrome'. Nephrol Dial Transplant. 2006:21:672-6.

23. Chesney RWMD. The idiopathic Nephrotc Syndrome. Curr Opin Pediatr. 1999:11:158-64.

24. Fuchshuber A, Gribouval O, Ronner V, Kroiss S, Karle S, Brandis M, Hildebrandt F. Clinical and genetic evaluation of familial steroid-responsive nephrotic syndrome in childhood. J Am Soc Nephrol. 2001;12(2):374-8. 
25. Kim JS, Bellew CA, Silverstein DM, Aviles DH, Boineau FG, Vehaskari VM. High incidence of initial and late steroid resistance of initial and late steroid resistance in childhood nephrotic syndrome. Kidney Int. 2005;68:1275-81.

26. Nammalwar BR, Vijayakumar M, Prahlad N. Experience of renal biopsy in children with nephrotic syndrome. Pediatr Nephrol. 2006;21:286-8.

27. Behrmann RE, Kliegmann RM, Jenson HB. Nephrotic Syndrome. In: Nelson textbook of pediatrics. 17th ed. Philadelphia, PA: Saunders; 2004. p. 1753-8.

28. Batinic D, Scukanec-Spoljar M, Milosevic D, et al. Clinical and histological characteristics of biopsy proven renal diseases in Croatia. Acta Med Croatica. 2007:61:361-4.

29. Choi IJ, Joeng HJ, Han DS, Lee JS, Choi KH, Kang SW, Ha SK, Lee HY, Kim PK. An analysis of 4514 cases of renal biopsy in Korea. Yonsei Med J. 2001;42: 247-54.

30. De Almeida JL, Campos LM, Paim LB, Leone C, Koch VH, Silva CA. Renal involvement in Henoch-Schönlein purpura: a multivariate analysis of initial prognostic factors. J Pediatr. 2007:83:295-66.

31. Nong BR, Huang YF, Chuang CM, Liu CC, Hsieh KS. Fifteen-year experience of children with Henoch-Schönlein purpura in southern Taiwan 1991-2005. J Microbiol Immunol Infect. 2007;40:371-6.

32. Coppo R, Amore A, Gianoglio B. Clinical features of Henoch Schönlein Purpura. Ann Med Interne. 1999;150:143-50.

33. Kasahara T, Hayakawa H, Okubo S, Okugawa T, Kabuki N, Tomizawa S, Uchiyama M. Prognosis of acute poststreptococcal glomerulonephritis (APSGN) is excellent in children, when adequately diagnosed. Pediatr Int 2001;43:364-7.

34. Niimi K, Ide K, Tsuru N. Five cases of acute poststreptococcal glomerulonephritis with acute renal failure and nephrotic syndrome. Nippon Jinzo Gakkai Shi. 2002;44:29-33.

35. Rodriguez-Iturbe B, Musser JM. The current state of poststreptococcal glomerulonephritis. J Am Soc Nephrol. 2008;19(10):1855-64.

36. Jellouli M, Maghraoui S, Abidi K, et al. Outcome of rapidly progressive glomerulonephritis post-streptococcal disease in children. Nephrol Ther. 2015;11(6):487-91.

37. Al-Rasheed SA, Al-Mugeiren MM, Al-Salloum AA, Al-Sohaibani MO Childhood renal diseases in Saudi Arabia. A Clinicopathological study of 167 cases. Int Urol Nephrol. 1996;28:607-13.

38. Adhikari M, Coovadia HM, Chrystal V, Morel-Maroger L. Absence of 'true' minimal change nephrotic syndrome in African children in South Africa. J Trop Med Hyg. 1983:86:223-8.

39. Agarwal N, Phadke KD, Garg I, Alexander P. Acute renal failure in children with idiopathic nephrotic syndrome. Pediatr Nephrol. 2003;18:1289-92.

40. Okpechi IG, Ameh Ol, Bello AK, et al. Epidemiology of histologically proven glomerulonephritis in Africa: a systemic review and meta-analysis. PLoS One. 2016;11(3):e0152203.

41. Buuren AJ, Bates WD, Muller N. Nephrotic Syndrome in Namibian children. S Afr Med J. 1999:89:1088-91.

42. Thomson PD. Renal problems in black south African children (occasiona survey). Pediatr Nephrol. 1997;11:508-12.

43. Hendrickse RG. Epidemiology and prevention of kidney disease in Africa. Trans R Soc Trop Med Hyg. 1980;74:8-16.

44. Anochie I, Eke F, Okpere A. Childhood nephrotic Syndrome: change in pattern and response to steroids. J Natl Med Assoc. 2006;98:1977-81.

45. Eke FU, Eke NN. Renal disorders in children: a Nigerian study. Pediatr Nephrol. 1994;8:383-6.

46. Okoro BA, Okafor HU, Nnoli LU. Childhood nephrotic syndrome in Enugu. Nigeria West Afr J Med. 2000;19:137-41.

Ready to submit your research? Choose BMC and benefit from:

- fast, convenient online submission

- thorough peer review by experienced researchers in your field

- rapid publication on acceptance

- support for research data, including large and complex data types

- gold Open Access which fosters wider collaboration and increased citations

- maximum visibility for your research: over $100 \mathrm{M}$ website views per year

At BMC, research is always in progress.

Learn more biomedcentral.com/submissions 